\title{
Combination sandwich therapy using cyanoacrylate and polyglycolic acid sheets for refractory enterocutaneous fistula closure
}

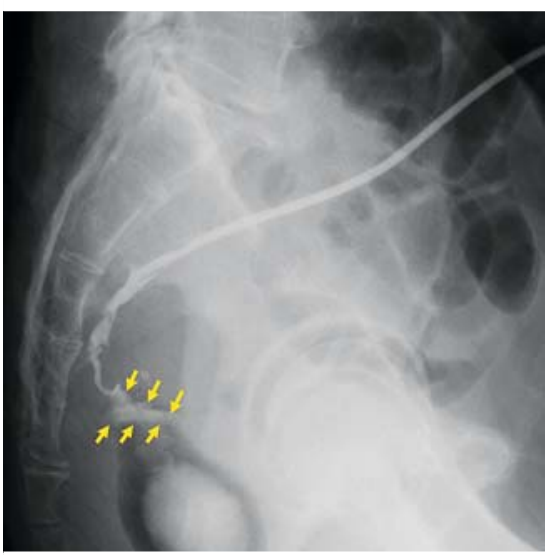

- Fig. 1 Radiograph with contrast injected via the intraoperatively inserted drain showing an anastomotic leak measuring $3 \mathrm{~cm} \times 6 \mathrm{~mm}$ (yellow arrows).

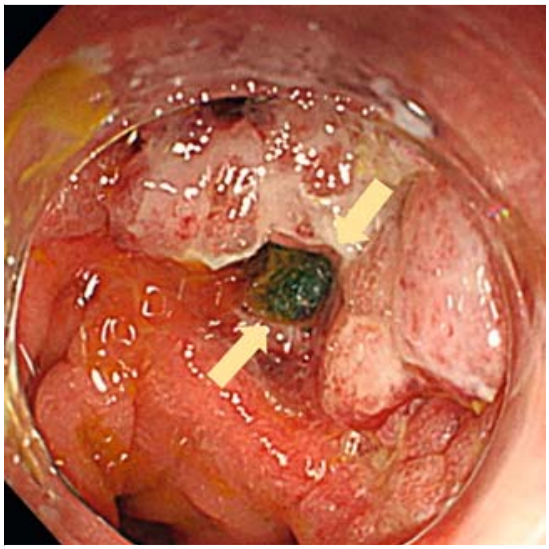

- Fig. 4 Endoscopic image showing the sections of polyglycolic acid sheet (orange arrows) compressed into the proximal side of the fistula.

Treating refractory gastrointestinal fistulas is a challenge and often necessitates long hospitalization times. A less invasive endoscopic approach for early complete closure is needed $[1,2]$. Possible closure methods include simple filling therapy with cyanoacrylate (Histoacryl; B. Braun, Tokyo, Japan) [3] or polyglycolic acid (PGA) sheets (NEOVEIL; Gunze, Osaka, Japan) [4], or closure with an over-thescope clip (OTSC; Ovesco Endoscopy AG,

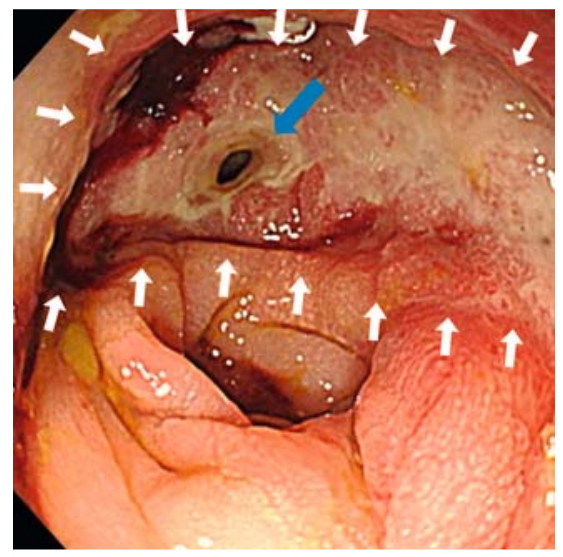

- Fig. 2 Endoscopic image showing the refractory enterocutaneous fistula $(6 \mathrm{~mm}$ in diameter, $3 \mathrm{~cm}$ long; blue arrow) within the granulated cavity of the anastomotic site (white arrows).

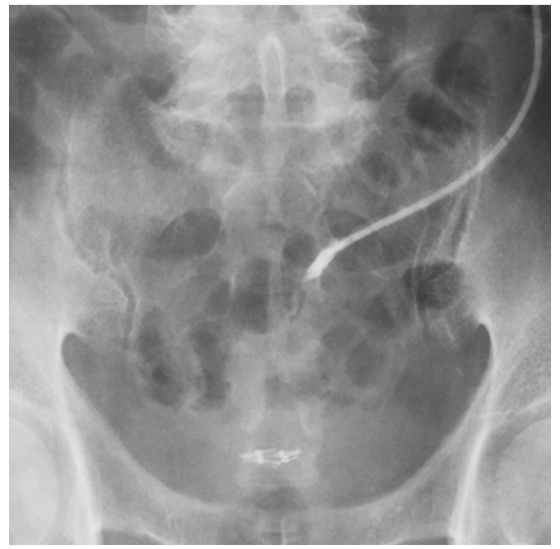

- Fig. 5 Radiograph with contrast injected via the drain confirming successful fistula closure.

Tübingen, Germany) [5], but none have provided satisfactory outcomes. We introduce a novel combination therapy using cyanoacrylate and PGA sheets for fistula closure.

A 71-year-old man underwent low anterior resection for advanced rectal cancer. Contrast radiography via the intraoperatively inserted drain 4 days later revealed an anastomotic leak ( $\triangleright$ Fig.1). Despite conservative therapy for 1 month, the

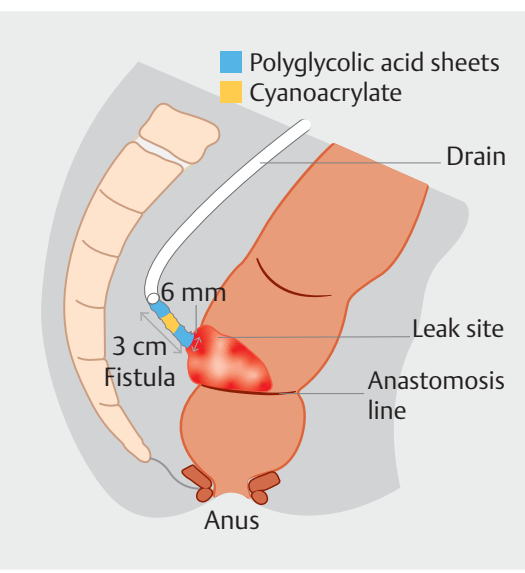

- Fig. 3 Schematic showing endoscopic combination sandwich therapy with polyglycolic acid (PGA) sheets, cyanoacrylate, and PGA sheets to close the refractory enterocutaneous fistula.

leak progressed to become a refractory enterocutaneous fistula $(6 \mathrm{~mm}$ in diameter, $3 \mathrm{~cm}$ long) within the granulated cavity of the anastomotic site ( $\mathbf{F i g . 2}$ ). An OTSC was considered unsuitable because of concerns over endoluminal stenosis after deployment and limited ability to treat the large indurated defect. Instead, we placed small pieces of PGA sheet in the fistula endoscopically, and followed this by spraying with fibrin glue (Beriplast P Combi-Set; CSL Behring, Pennsylvania, USA), but this did not result in successful closure.

Endoscopic combination sandwich therapy was therefore attempted 7 days later using PGA sheets, cyanoacrylate, and PGA sheets ( Fig. 3; Video 1). First, after retracting the drain $2 \mathrm{~cm}$ toward the cutaneous side, we placed small pieces of PGA into the distal side of the fistula. Next, $0.5 \mathrm{~mL}$ of cyanoacrylate, followed by $5 \mathrm{~mL}$ of $50 \%$ glucose, was injected to consolidate the fistula route. Then, pieces of PGA sheet with fibrin glue were compressed into the proximal side of the fistula (\$ Fig.4). Contrast radiography 9 days later via the drain confirmed successful fistula closure ( $\triangleright$ Fig.5), and the 


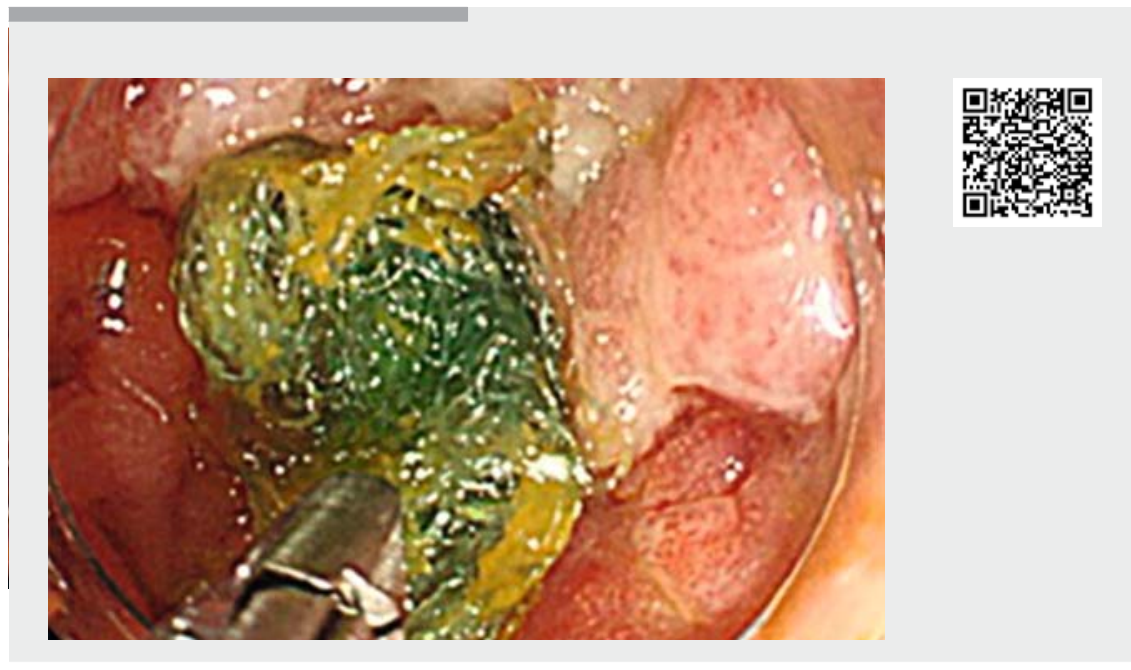

Video 1 A novel endoscopic combined sandwich therapy using polyglycolic acid (PGA) sheets, cyanoacrylate, and PGA sheets to completely close a refractory enterocutaneous fistula.

patient was discharged after drain removal. No recurrence has developed during the 4-month follow-up period.

This method represents a novel effective option to treat refractory gastrointestinal fistulas.

Endoscopy_UCTN_Code_TTT_1AQ_2AG

Competing interests

The authors declare that they have no conflict of interest.

The authors

Naoya Tada ${ }^{1}$, Hideki Kobara ${ }^{1}$, Noriko Nishiyama ${ }^{1}$, Ken Ishimura², Kunihisa Uchita ${ }^{3}$, Akira Nishiyama ${ }^{4}$, Tsutomu Masaki ${ }^{1}$

1 Department of Gastroenterology and Neurology, Faculty of Medicine, Kagawa University, Kagawa, Japan

2 Department of Gastroenterological Surgery, Kagawa Saiseikai Hospital, Kagawa, Japan

3 Department of Gastroenterology, Kochi Red Cross Hospital, Kochi, Japan

4 Department of Pharmacology, Faculty of Medicine, Kagawa University, Kagawa, Japan
Bibliography

Endoscopy 2021; 53: E114-E115

DOI 10.1055/a-1208-3005

ISSN 0013-726X

published online 17.7.2020

(C) 2020. Thieme. All rights reserved.

Georg Thieme Verlag KG, Rüdigerstraße 14,

70469 Stuttgart, Germany

\section{ENDOSCOPY E-VIDEOS}

https://eref.thieme.de/e-videos

回回 Endoscopy E-Videos is a free access online section, reporting 回: on interesting cases and new techniques in gastroenterological endoscopy. All papers include a high quality video and all contributions are freely accessible online.

This section has its own submission website at https://mc.manuscriptcentral.com/e-videos

Hideki Kobara, MD, PhD

Department of Gastroenterology and Neurology, Faculty of Medicine, Kagawa University, 1750-1 Ikenobe, Miki, Kita, Kagawa 761-0793, Japan

Fax: +81-87-8912158

kobara@med.kagawa-u.ac.jp

\section{References}

[1] Owen RM, Love TP, Perez SD et al. Definitive surgical treatment of enterocutaneous fistula outcomes of a 23-year experience. JAMA Surg 2013; 148: 118-126

[2] Lloyd DA, Gabe SM, Windsor AC. Nutrition and management of enterocutaneous fistula. Br J Surg 2006; 93: 1045-1055

[3] Toshiyasu O, Masaki N, Mikihito $\mathrm{N}$ et al. Endoscopic treatment of esophageal fistulas after esophagectomy with injection of an alpha-cyanoacrylate monomer: a phase II study. Endosc Int Open 2018; 6: E1093E1099

[4] Nakano Y, Takao T, Morita Y et al. Endoscopic plombage with polyglycolic acid sheets and fibrin glue for gastrointestinal fistulas. Surg Endosc 2019; 33: 1795-1801

[5] Kobara H, Mori H, Nishiyama $\mathrm{N}$ et al. Overthe-scope clip system: A review of 1517 cases over 9 years. J Gastroenterol Hepatol 2019; 34: $22-30$ 